\title{
LA ESCRITURA DE GÉNEROS ESPECIALIZADOS Y SU RELACIÓN CON LA IDENTIDAD DISCIPLINAR. ESTUDIO DE CASO EN INGENIERÍA INDUSTRIAL
}

\author{
A ESCRITA de GÊNEROS ESPECIALIZAdos E SUA RELAÇÃo COM A IDENTIDAdE DiSCIPLINAR. \\ ESTUDO DE CASO NA ENGENHARIA INDUSTRIAL
}

\author{
Writing Specialized Genres - Its Relation to Disciplinary Identity. A Case \\ STUDY IN INDUSTRIAL ENGINEERING
}

\author{
Emilce Moreno Mosquera \\ Licenciada en Español y Filología \\ Clásica, y Magíster en Lingüística, \\ Universidad Nacional de Colombia, \\ Bogotá. Doctora en Educación, \\ Universidad Pedagógica Nacional, \\ Bogotá. Profesora de áreas \\ relacionadas con el campo de la \\ didáctica de la lectura y la escritura \\ y afines a la lingüística, Facultad de \\ Educación, Pontificia Universidad \\ Javeriana. \\ Carrera $7 \mathrm{~N}^{\circ}{ }^{4} 42-27$, Edificio Lorenzo \\ Uribe, Bogotá, Colombia \\ moreno-e@javeriana.edu.co \\ https://orcid. \\ org/0000-0003-4058-5691
}

\begin{abstract}
RESUMEN
En el presente artículo se analiza cómo la escritura de un plan de mercadeo se conecta con el trabajo de investigación de mercados, y cómo mediante la escritura de dicho plan los estudiantes incorporan prácticas de literacidad disciplinar. La información recogida mediante la observación de clases y entrevistas a treinta estudiantes de octavo semestre de ingeniería industrial permitió demostrar la tesis de que la escritura progresiva y auténtica de géneros especializados puede preparar al estudiante no solo para la comprensión de dichos géneros, sino también para desarrollar hábitos mentales o formas de conocer, hacer, pensar y actuar (Gee, 1996), asociados con su trabajo disciplinar. Se concluye que las prácticas de escritura situadas pueden ofrecer un marco de explicación sobre el uso de los géneros académicos, los modos de acceder y construir conocimiento y desarrollar identidades que favorezcan el aprendizaje de dominios específicos.
\end{abstract}

Palabras clave: escritura; literacidad disciplinar; género; función epistémica de la escritura; identidad disciplinar.

\begin{abstract}
RESUMO
No presente artigo, analisamos como a escrita de um plano de marketing vinculase com o trabalho de pesquisa de mercados, e como por meio da escrita desse plano os estudantes incorporam práticas de letramento disciplinar. A informação coletada através da observação de aulas e entrevistas com trinta estudantes do oitavo semestre de engenharia industrial permitiu mostrar a tese de que a escrita progressiva e autêntica de gêneros especializados pode preparar o estudante não apenas para compreender esses gêneros, mas também para desenvolver hábitos mentais ou formas de conhecer, fazer, pensar e agir (Gee, 1996), associados com seu trabalho disciplinar. Concluímos que as práticas de escrita situadas podem oferecer um referencial de explicação sobre a utilização dos gêneros acadêmicos e os modos de acessar e construir conhecimento, assim como desenvolver identidades que favoreçam a aprendizagem de domínios específicos.
\end{abstract}

Palavras chave: escrita; letramento disciplinar; gênero; função epistêmica da escrita; identidade disciplinar.

Recibido: 2018-11-16 / Aceptado: 2019-03-20 / Publicado: 2019-05-20

DOI: $10.17533 /$ udea.ikala.v24n02a04 


\section{Abstract}

This paper analyses how writing a marketing plan is related to market research work, and how in writing that plan, students get acquainted with disciplinary literacy practices. Data gathered through class observation and interviews held with thirty students in their eighth semester of industrial engineering allowed us to prove the hypothesis that ongoing and authentic writing of specialized genres may help train students not only to better comprehend those genres, but also to develop mental habits or approaches to learning, doing, thinking, and behaving (Gee, 1996), related to their work within their disciplinary domain. We conclude that situated writing practices may provide some framework to explain how academic genres work, and how knowledge can be reached and built, as well as how to develop identities that benefit learning specific domains.

Keywords: writing; disciplinary literacy; genre; epistemic role of writing; disciplinary identity. 


\section{Introducción}

Los ingenieros deben ser capaces de aplicar enfoques innovadores para resolver problemas del mundo real. De ahí que su profesión requiera que piensen críticamente, y la escritura se constituye en una herramienta pedagógica fundamental para ello (Bean, 2011). El presente estudio analiza una experiencia de aula en el marco de la asignatura Logística de Mercado (LM, en adelante), ${ }^{1}$ en una universidad colombiana en la que los estudiantes debían desarrollar un plan de mercadeo. El trabajo requirió que los participantes adoptaran prácticas de lectura y escritura específicas de su disciplina, lo que se conoce como un proceso de enculturación, ${ }^{2}$ con el objetivo de que aprendieran este género y adoptaran discursos propios de su profesión. En el marco de investigaciones sobre géneros acádemicos existen manuales que se ocupan de los géneros que los estudiantes deben aprender, como el resumen, la reseña, el artículo de investigación (Nogueira, 2003; Klein, 2007; Cisneros y Olave, 2012; Natale, 2012; Hernández-Zamora, 2016; Navarro y Aparicio, 2018). Así mismo, se encuentran estudios que abordan la estructura lingüística y retórica de los géneros discursivos (Bunton, 1999;

1 Uno de los focos de esta clase es la investigación de mercados, es decir, el estudio de la relación entre "el consumidor, el cliente y el público con el especialista de marketing a través de información, que se utiliza para identificar y definir oportunidades y los problemas de marketing, generar, perfeccionar y evaluar las acciones de marketing, monitorear el desempeño de las estrategias" (AMA, citado en Rivera-Camino, 2009, p. 190).

2 Se entiende el proceso de enculturación siguiendo a Prior y Bilbro (2012), quienes lo relacionan con el aprendizaje de los géneros académicos, es decir, que los estudiantes universitarios se vinculan paulatinamente a espacios sociales y disciplinares, organizados por expertos que manejan unas prácticas y unos géneros discursivos (orales y escritos) que les permiten cumplir unos fines comunicativos afines a su profesión. En ese proceso, el vínculo entre el experto y el novato genera posibilidades de conectar "formas discursivas, pero también prácticas que se trasladan y se recontextualizan a través de escenarios y hábitos que, a su vez, implican ideologías y cambios en las identidades de los participantes" (p. 14).
Paltridge, 2002; Shaw, 2000; Swales, 1990, 2004; Swales y Lindemann, 2002). En el caso particular de la ingeniería también se encuentran estudios que abordan la relación de la lectura y la escritura en el aprendizaje profesional (Artemeva, 2005, 2009; Baillie y Johnson, 2008; Herrington, 1985; Marinkovich, Sologuren y Shawky, 2018; NarváezCardona, 2016; Stagnaro y Natale, 2015; Winsor, 1990, 1999, 2003). Se trata de literatura que puede contribuir a la comprensión de los géneros textuales mediante prácticas de enseñanza y aprendizaje situadas.

Este artículo analiza el vínculo entre la escritura del género plan de mercadeo, con el contexto de la clase y la identidad disciplinar de los ingenieros industriales. Se asume que el uso de géneros especializados permite a los estudiantes universitarios aprender, construir y evaluar el conocimiento en sus culturas disciplinares (Nesi y Gardner, 2012).

Se reconoce la literacidad disciplinar como marco de interpretación de las prácticas observadas, las cuales reflejan formas de lectura, escritura y oralidad y su nexo con la construcción del conocimiento profesional. Este tipo de literacidad "se da en el marco de un dominio específico y restringido; una disciplina donde la lectura y la escritura se ven como prácticas inherentes y esenciales, las cuales pueden ser reproducidas, aprendidas y enseñadas" (Montes y López-Bonilla, 2017, p. 165). De ahí que las literacidades disciplinares exhiban diferencias culturales en cuanto al uso de la información, la naturaleza y las convenciones del lenguaje, los modos de abordar los problemas, etc. Esto va en la misma línea de lo planteado por Street (2005) sobre las literacidades: "los modos como la gente aborda la lectura y la escritura están en sí mismos enraizados en concepciones del conocimiento, la identidad y el ser" (p. 418).

De acuerdo con lo anterior, en este artículo se abordan las siguientes preguntas: ¿cómo la clase de Logística de Mercado favorece la escritura del plan de mercadeo y contribuye a la construcción de la identidad disciplinar de los ingenieros?, y 
¿cómo perciben los estudiantes el papel de la escritura en el contexto de la clase?

\section{El género plan de mercadeo}

En la formación universitaria, los géneros discursivos orales y escritos están conectados a convenciones, normas y formas compartidas de negociar, producir y divulgar conocimiento, como lo plantea Hyland (2004[2000]), cuando analiza las prácticas de escritura y su relación con los géneros disciplinarios.

Las prácticas comunicativas disciplinarias involucran un sistema de compromiso social adecuado al contenido y a los colegas. La escritura que las disciplinas producen, apoyan y autorizan, por lo tanto, puede verse vinculada a formas de poder en esas organizaciones. Son representaciones de discursos legítimos que ayudan a definir y mantener epistemologías particulares y fronteras académicas. Dado que los textos se escriben para entenderse dentro de ciertos contextos culturales, el análisis de géneros clave puede proporcionar información sobre lo que está implícito en estas culturas académicas, sus operaciones retóricas acostumbradas que revelan las percepciones de los valores individuales y creencias de los escritores. Por lo tanto, los géneros no son solo tipos de texto; también implican prácticas institucionales particulares de aquellos que los producen, distribuyen y consumen (Fairclough, 1992). Los propósitos individuales y sociales interactúan con las características del discurso en cada elección y en cada género, y para analizarlos hay que aprender sobre cómo cada disciplina ve el conocimiento y se define a sí misma (pp.11-12, traducción propia).

De lo anterior se colige que las prácticas y los géneros varían de acuerdo a los marcos disciplinares y conllevan el desarrollo de habilidades comunicativas orales y escritas propias del ámbito universitario. En esa medida, los géneros discursivos como clases relativamente estables de textos orales y escritos son reconocidos y producidos en diferentes actividades humanas. Así mismo, reflejan condiciones específicas en relación a la estructura, el estilo, la gramática y el vocabulario (Bajtín, 1985).

$\mathrm{Al}$ ingresar a la universidad, los estudiantes universitarios necesitan aprender los géneros de escritura académica, así como, entender las convenciones y los registros específicos de sus disciplinas. Además, escribir un género no solo requiere manejar un conjunto de reglas o formas retóricas, sino también el contexto y la comunicación con una audiencia que tiene ciertos entendimientos y expectativas de ese género (Bazerman, 2011). De otro lado, se encuentra la interconexión entre la adquisición de un género y el desarrollo de la identidad profesional, vinculada a la relación entre el experto y el novato con la actividad específica. Las personas se comprometen con determinadas identidades que desarrollan a través del acceso y la participación en géneros textuales en sus comunidades. De esta manera, "el género moldea las intenciones, los motivos, las expectativas, la atención, la percepción, el afecto y el marco interpretativo" (Bazerman, 2002, p. 14). Lo anterior resulta fundamental para entender cómo el dominio de los géneros discursivos permite a los estudiantes novatos vincularse a sus comunidades para desarrollar su identidad como profesionales.

El género plan de mercadeo se caracteriza por dar cuenta de las acciones estratégicas que una empresa debe realizar para satisfacer las necesidades de un mercado objetivo. Por ello, debe investigarse el contexto al cual va dirigido, documentar las necesidades, los gustos y las preferencias de clientes reales y potenciales. De modo que la preparación del documento implique hacer un diagnóstico y fundamentar la iniciativa basados en el conocimiento del mercado meta.

Para conocer y evaluar la capacidad de la empresa se usa la matriz DAFO, ${ }^{3}$ se definen objetivos reales, se planean estrategias de mercadeo ajustadas a tiempos y costos, se plantean indicadores de seguimiento, se fidelizan los clientes, etc. La Figura 1 resume los momentos claves en la escritura del plan de mercadeo.

3 El análisis DAFO es una herramienta de planificación estratégica, diseñada para realizar un análisis interno (fortalezas y debilidades) y externo (oportunidades y amenazas) en la empresa (analisisfoda.com). 


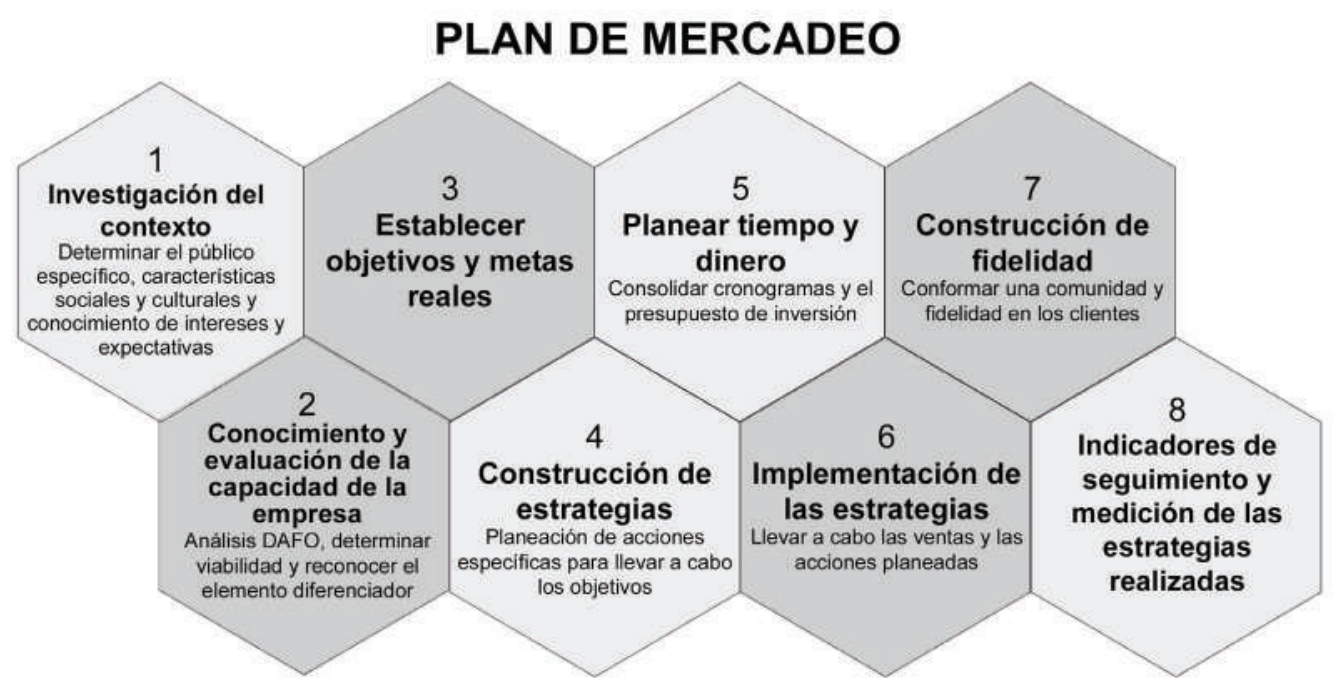

Figura 1 Momentos claves del plan de mercadeo

Función epistémica de la escritura e identidad disciplinar

El lenguaje, las normas, las convenciones y más específicamente los códigos empleados en cada disciplina se relacionan con prácticas epistémicas, esto es, "formas específicas por las que se proponen, justifican, evalúan y legitiman los contenidos en un determinado marco teórico disciplinar" (Duschl y Osborne, citados por Navarro y Revel Chion, 2013, p.45). De este modo, la promoción de diferentes tareas de aprendizaje asociadas a la lectura, la escritura, la argumentación, la oralidad, etc. en la universidad contribuye a desarrollar criterios epistémicos y posibilitar el proceso de enculturación en la comunidad académica. Yendo más allá, el afianzamiento de dichas prácticas entre los estudiantes puede vincularse al conocimiento de su campo y al desarrollo de su identidad disciplinar, es decir, se desarrollan discursos y prácticas en las que los estudiantes se involucran de acuerdo a su profesión para producir, representar y criticar conocimiento en su cotidianidad. Las identidades disciplinares son "las representaciones de los sujetos mismos que reflejan hábitos de la mente, las prácticas y los discursos - o las formas de conocer, hacer, pensar y actuar - "(Gee, citado por Moje, 2010, p. 72).
Estas prácticas resaltan el "potencial epistémico de la escritura” (Camps y Castelló, 2013; McCutchen, Teske y Bankston, 2008; Wells, 1990), puesto que son mediaciones fundamentales para el aprendizaje y la enculturación en marcos disciplinares específicos. Como lo afirman varios teóricos, los textos y los géneros especializados ejercen una influencia en relación con formas de leer y escribir ligadas a la experticia disciplinar (Bazerman, 1985; Berkenkotter y Huckin, 1995; Haas, 1994; Wineburg, 1991), y a su vez, estos patrones pueden vincularse a procesos de enseñanza.

\section{Método}

Se trata de un estudio de caso que explora

un sistema limitado, contemporáneo de la vida real (un caso) o múltiples sistemas acotados (casos) a lo largo del tiempo, a través de una recopilación de datos detallada y en profundidad que involucra múltiples fuentes de información [...] y reporta una descripción del caso y temas del caso (Creswell, 2013, p. 97, traducción propia).

Para ello, se delimita el objeto estudiado en relación con las particularidades del caso, en el marco de su complejidad, específicamente, las prácticas de escritura en la clase de LM. Se da cuenta de 
actividades de enseñanza que involucran escribir para aprender, por lo cual se hace una descripción de situaciones cotidianas, de usos y percepciones en torno al dominio del género plan de mercadeo en la formación de ingenieros industriales.

El estudio se llevó a cabo durante el primer semestre de 2018 en la carrera de Ingeniería Industrial de la Pontificia Universidad Javeriana en el curso de LM, el cual es teórico-práctico y tiene una intensidad horaria de 4 horas semanales. Se observaron y grabaron clases durante 10 semanas y el investigador tomaba registro de estas adicionalmente mediante el formato de De Tezanos (2004), lo cual a su vez permitió indagar in situ el significado que le otorgan los estudiantes y la profesora a tareas de lectura y escritura. En este curso se desarrollaban competencias para entender la relación entre los conceptos de gestión de mercados, gestión de cadena de suministros y, con base en estos conceptos, elaborar un plan de mercadeo ${ }^{4}$. Éste es un género implicado en la formación de estudiantes de cuarto año sin experiencia en el medio laboral y que han reflexionado especialmente sobre la creación de empresas a partir de análisis de casos.

El grupo observado estaba conformado por 30 estudiantes de octavo semestre, con énfasis de logística. Se aplicó una entrevista escrita ${ }^{5}$ a todos

4 Entre los objetivos que se plantean en este curso están: 1) Desarrollar en el estudiante competencias para entender la relación entre los conceptos de la gestión de cadena de suministros y la elaboración de un plan de mercado. 2) Facilitar en el estudiante la visualización y diagnóstico de las condiciones del entorno, para el manejo, administración y comercialización de bienes y servicios. 3) Dotar al estudiante de herramientas cuantitativas y cualitativas para realizar la gestión de mercados, luego de identificar y cuantificar la demanda de productos o servicios. 4) Desarrollar en el estudiante las competencias para elaborar un plan de mercadeo que responda de manera adecuada a la relación entre los elementos de la mezcla. 5) Suministrar al estudiante herramientas para articular de manera exitosa los elementos de la gestión de cadenas de suministro con la elaboración de planes de mercadeo (Programa del curso facilitado por el profesor).

5 Se optó por este tipo de entrevista debido a que las sesiones estaban establecidas en el calendario y se convino ellos, indagando por sus percepciones en torno al desarrollo del género, asuntos procedimentales, retóricos, gramaticales y el nexo con su identidad disciplinar como ingenieros industriales. Se realizó un análisis cualitativo-interpretativo que buscó “《traducir» todos los significados en un material, los cuales eran de interés dentro de las categorías de un marco de codificación" (Schreier, 2012, p.5). El trabajo de codificación se centró en unidades discursivas relacionadas con la escritura del plan de mercadeo y su contribución a la construcción de una identidad disciplinar. Dado que se trató de una investigación exploratoria con una muestra relativamente pequeña de entrevistados no se consideró pertinente cuantificar los datos. Los resultados no pretenden ser generalizables; más bien, ofrecen respuestas preliminares al potencial epistémico de la escritura en la dinámica de la clase analizada. Para la observación, registro y análisis de las clases se retomó el modelo de Hamilton (2000), el cual como se explicará en el siguiente apartado considera los participantes, el escenario, los artefactos, las actividades, como elementos centrales implicados en los eventos letrados, es decir, aquellos episodios observables de lectura o escritura que se dan en contextos sociales específi$\cos$. En ese sentido, los textos tienen unas funciones de acuerdo al escenario en que se emplean (Barton y Hamilton, 2000).

Para el análisis de las entrevistas, se definieron varias categorías, que se desglosan en la Tabla 1.

\section{Resultados}

\section{Contextualización y análisis de la clase de $\mathbf{L M}$}

En las clases se observó que se buscaba la interpretación de textos a través de la generación de un espacio dialógico, además de un trabajo progresivo de producción del plan de mercadeo.

con la profesora enviarla a sus correos y darles una directriz muy clara de lo solicitado en el instrumento, además de sensibilizarlos sobre la importancia de su diligenciamiento como fuente de análisis de las tareas de lectura y escritura de la clase, de ahí que la respuesta fuera masiva. 
Tabla 1 Categorías identificadas en entrevistas realizadas a estudiantes de la clase Logística de Mercados

\begin{tabular}{ll}
\hline \multicolumn{1}{c}{ Categoría } & \multicolumn{1}{c}{ Definición } \\
\hline $\begin{array}{l}\text { Cuestiones relativas al } \\
\text { proceso de escritura }\end{array}$ & Formas de planear el texto o aspectos relacionados con citación, coherencia, cohesión, puntuación, etc. \\
El género plan de mercadeo & Aspectos referidos a las partes del plan de mercadeo: objetivos, indicadores, propuesta de valor, mercado objetivo, etc. \\
Identidad disciplinar & $\begin{array}{l}\text { Hábitos de la mente o formas de conocer, hacer, pensar y actuar (Gee, 1996), asociados con el trabajo disciplinar. En el } \\
\text { desarrollo del plan de mercadeo, la identidad incide en la toma decisiones. }\end{array}$ \\
\hline
\end{tabular}

Fuente: Elaboración propia.

Como se explicó anteriormente se trata de una clase teórico-práctica. Para cada sesión se asignaban las lecturas a los estudiantes, quienes debían explicar los temas del curso a través de videos que incluían la explicación de conceptos y ejemplos. Cada una de estas explicaciones era aprovechada para que los estudiantes adquirieran criterios para tomar decisiones sobre recopilar, tabular y analizar datos cuantitativos y cualitativos, todo lo cual les serviría para diseñar el plan identificando las oportunidades de marketing. Esto constituye una serie de elementos visibles y no visibles en los eventos letrados, como se presentan en las Tablas 2 y 3.

En el plan de mercadeo que realizan a lo largo de todo el semestre los estudiantes aplican los conceptos trabajados. El diseño del plan, junto con los talleres, pruebas escritas y la solución de problemas constituyen la estrategia de enseñanza de la profesora, y son fundamentales para articular lo aprendido en los textos. En el análisis se encontró que el abordaje de las lecturas está ligado a la investigación de mercados y se requiere la documentación sobre diferentes temas como: cadena de abastecimiento, mercadeo, técnicas de investigación e instrumentos, diseño, prueba piloto, tabulación, plan de mercadeo, etc.

Entre las principales estrategias de enseñanza e inclusión de las prácticas letradas están: la solución de problemas, la articulación de los temas tratados en la clase, las exposiciones y los talleres con el desarrollo del plan de mercadeo y la importancia que le atribuye a la oralidad. En la Tabla 4, se presenta la transcripción de un segmento de la clase.

Tabla 2 Elementos visibles en los eventos de literacidad de la clase Logística de Mercados

\begin{tabular}{|c|c|}
\hline & Elementos visibles en los eventos de literacidad \\
\hline Participantes & La docente y los estudiantes de Ingeniería Industrial de octavo semestre. \\
\hline Escenario/contexto & La clase Logística de Mercado. \\
\hline \multirow[t]{5}{*}{ Artefactos } & Ballou, R. (1999). Business Logistics Management. México: Prentice Hall. \\
\hline & Malhotra, N. K, (2008). Investigación de mercados: un enfoque aplicado (5. Edición). México: Editorial Pearson \\
\hline & Educación. \\
\hline & Lamb, Charles W.; Hair, Joseph F. y McDaniel, Carl (2011). Marketing (11. " Ed.). México: Cengage Learning. \\
\hline & Pires, S., y Carretero, L. (2007). Gestión de la cadena de suministro. Madrid: McGraw Hill. \\
\hline Actividades & Desarrollo de la clase, explicaciones a partir de la lectura y las participaciones de los estudiantes, exposiciones de \\
\hline & temas específicos, resolución de problemas, interpelación a los estudiantes sobre lo leído, talleres. \\
\hline
\end{tabular}

Fuente: Elaboración propia con base en Hamilton (2000) 
Tabla 3 Elementos no visibles en los eventos letrados de la clase de Logística de Mercados

\begin{tabular}{ll}
\hline & Elementos no visibles en los eventos de literacidad \\
\hline Participantes & Los docentes y directivos de la carrera de ingeniería industrial. \\
Escenario/contexto & Estudio de las bases teóricas sobre mercadeo y logística relacionada con la cadena de suministro, como dominio. \\
Artefactos & Habilidad y conocimientos para realizar o desarrollar un problema de investigación de mercados, presentar un \\
plan de mercadeo como herramienta para gestionar la demanda. \\
Actividades & Entre las normas que regulan la interacción están: i. Compromiso de lectura previa y participar respondiendo \\
& a las preguntas de la profesora, ii. Compromiso de hacer los trabajos de la clase. iii. Compromiso de participar \\
& activamente en clase. \\
\hline
\end{tabular}

Fuente: Elaboración propia con base en Hamilton (2000)

En la transcripción presentada en la Tabla 4, se abordan los temas del plan de mercadeo y de la segmentación. ${ }^{6}$ Inicia con la presentación de un video en el que los estudiantes abordan un tema del plan, lo cual se constituye en una estrategia didáctica de la profesora para desarrollar habilidades comunicativas. Los estudiantes se refieren explícitamente a Lamb et al. (2011), como la fuente de documentación en que basan su discurso para el video. Además, como se muestra en el ejemplo, ellos tienen a la mano los textos, la profesora los invita a sacarlos.

La sesión continúa con las preguntas acerca de las ventajas competitivas y del atributo diferenciador del producto enunciado (Wash and Clean), concepto que resulta fundamental en la escritura del plan. Así mismo, se organizan grupos de trabajo para abordar el tema de la segmentación, que es introducido por la profesora. En estos fragmentos de clase se puede evidenciar el rol activo que ejercen los estudiantes y el tratamiento de los temas con fines a realizar el plan de mercadeo. De hecho, en esta sesión se definen sus características principales y se aborda el tema de la segmentación por ser fundamental en el análisis del contexto del

6 La segmentación de mercado es un proceso de marketing a través del cual una empresa divide o segmenta un mercado amplio en grupos más pequeños, cuyos integrantes tengan semejanzas o ciertas características en común. Establece diferencias entre los potenciales clientes de un producto y los clasifica de acuerdo a diferentes criterios (Economipedia.com). producto y del cliente. El anterior ejemplo muestra que los estudiantes hicieron aplicaciones de carácter investigativo, mediante entrevistas, análisis de datos, solución de problemas.

Los ingenieros en formación se basaban en las técnicas de los procesos de investigación de mercado como marco para tomar decisiones en las empresas $\mathrm{u}$ organizaciones en las cuales laborarían (por ejemplo, recopilar evidencias sobre la percepción en la venta de maquillaje). Debían pensar como ingenieros industriales en relación con los productos, las marcas, el conocimiento de los consumidores, las técnicas de investigación, los procesos de mercadeo estratégico, la cadena de abastecimiento, etc., y lograr que esta postura como ingenieros los llevara a alcanzar la productividad, la rentabilidad y la optimización en los planes que diseñaban.

\section{La escritura de géneros especializados en el marco del aula de clase de LM}

$\mathrm{Al}$ enfrentarse al planteamiento y la solución de problemas, los estudiantes aplicaban prácticas disciplinares en las que debían actuar y pensar como un ingeniero industrial. La lectura y la escritura les ofrecían una metodología para lograrlo. La solución de problemas se ubicaba en un marco de interacción que integraba: la explicación de la profesora, los conocimientos previos, las preguntas y los casos que les planteaba la docente o las relaciones que los estudiantes establecían 
Tabla 4 Transcripción de discusión en clase ${ }^{1}$

Estudiante 1: primero hablaremos de ¿qué es planeación? Es el proceso de anticipar los acontecimientos futuros y dictaminar estrategias para lograr los objetivos organizacionales en el futuro. En base a esto, Lamb y Hair definen el plan de mercadeo como un documento escrito que actúa con cualquiera de las actividades para el gerente de marketing. Para realizar un plan de mercadeo primero debes realizar una definición de la visión de negocio, es decir, la persona debe responder a la pregunta ¿en qué negocio estamos? Posteriormente, se debe dirigir un análisis de situación, en el cual se hace una estrategia del entorno, es decir, recolectar, interpretar información de eventos y relaciones en el entorno que pueden afectar el futuro de la organización o la implementación del plan de marketing. Después se debe realizar un establecimiento de los objetivos del plan de marketing, es decir, una declaración de lo que se quiere lograr. Dichos objetivos deben ser realistas, me[n]surables y definidos en el tiempo; también se debe realizar un análisis de la ventaja competitiva, es decir, cuáles son esas características únicas de mi empresa y mis productos que el mercado las recibe como significativos y superiores al de la competencia [Pone un video]

Para esto se debe realizar una descripción del mercado medio, es decir, cuál es ese grupo de individuos u organizaciones que comparte una o más características y que por ende tienen necesidades de productos relativamente similares [Pone un video]

Después se realiza la mezcla de marketing o también llamada las cuatro p, en la que se define el producto como un todo, la plaza que significa colocar los productos a la disposición del cliente en el momento y el lugar donde lo requiera, la promoción que incluye la publicidad y por último el precio. Por último, este documento escrito es llevado a las acciones y posteriormente se realiza una evaluación y control, basada en los objetivos planteados (...) [Pone un video] el Fondo Emprender presenta una estructura del plan de negocio en la que se responden 6 preguntas, para dárselas a conocer realizamos una entrevista a un emprendedor interesado en la convocatoria:

"Hola, chicos, cómo están, mi nombre es Martín. Soy el vicepresidente de ventas de Wash and Clean, que es el nuevo emprendimiento social enfocado al lavado de ropa. Bueno, nos encargamos de brindar servicio de lavado de ropa a personas y empresas que lo requieran, y las personas que lavan son amas de casa 0 amos de casa o personas que quieran generar un ingreso extra para ellos; entonces, esas dos partes y la parte que nos pagan a nosotros es la parte que le pagamos a ellos. Bueno, nosotros suplimos dos tipos de necesidades diferentes, dos tipos de clientes fijos, los primeros son personas que en su casa no quieren lavar la ropa porque simplemente no tienen tiempo para hacerlo. Los otros están en centros comerciales, como por ejemplo las peluquerías, toallas y demás. (...) Bueno, la solución que nosotros proponemos [Wash and Clean] es un servicio puerta a puerta muchísimo más económico con respecto a la competencia, 1400 pesos en promedio. [...] [Segmento de la entrevista realizada por los estudiantes a un emprendedor]

Profesora: muchísimas gracias, entonces la tarea que ustedes tienen que responder, insisto, no es solo la idea de negocio, sino la realización de ese plan de negocio, en parejas por favor, a la cuenta de 15 respondan lo siguiente: ¿cuáles fueron las 6 preguntas que propone el video que debe usted responder si se va a presentar al fondo de proyecto? y dos ¿qué es un crédito condonable? por parejas, y ya llegó don Pipe, venga y se sienta aquí conmigo, para ponerle emoción a esto y cuento hasta 15, icalladitos! Uno, dos...

$[\ldots]$

Profesora: ¿Qué es una ventaja competitiva?

Estudiante 5: Pues yo lo veo como un sinónimo de atributo de diferenciador.

Profesora: Sí y no; está basado en teoría, debería estar basado en el atributo diferenciador, es aquello por lo que el mercado me va a comprar a mí y no a la competencia iojo! pero ¿cuál es la diferencia entre una ventaja competitiva y una ventaja comparativa? Investiguen. ok, entonces, cuando uno habla para mí, cuando se habla de emprendimiento realmente el emprendimiento debe causar emoción si yo hablo de emprendimiento y todo el mundo está dormido, si yo le pregunto a usted cuál es su intención en la vida y usted me dice ser emprendedor, pero se duerme, pues realmente para mí ese tipo de comportamiento lo que me está permitiendo percibir es que realmente no es ese su texto. Entonces, la invitación es: si se va a dedicar a eso, si quiere convertir esto en un hecho, se puede, lo que hemos hablado sobre rasgos Bodytech, Koala, el negocio Wash and Clean iqué era lo que hacía, ingeniero Hernán?

Estudiante 6: Realizaba un servicio de lavandería puerta a puerta, tanto a personas, como compañías.

Profesora: ¿cuál era el factor diferenciador?

Estudiante 6: Ellos no manejaban ningún local de lavandería, sino que prestaban servicio puerta a puerta, pero la ropa era enviada a personas que quisieran ejercer la labor y la lavaban desde sus casas.

Profesora: esa es una lavandería que tiene servicio a domicilio ¿Cuál es el atributo diferenciador? Yo no le he visto el atributo diferenciador ¿Quién es el que valida el atributo diferenciador? El cliente, al cliente le llega cómo el producto.

Estudiante 7: lavado, planchado, con aroma y bolsita.

Profesora: y ¿cuál es la diferencia con la lavandería de la esquina?

Estudiante 7: pues que el precio es de $\$ 1400$

Profesora: el precio, ahora ¿cómo logra ese precio?

1 Se señalan en cursiva los segmentos que son sugerentes para dar cuenta de las prácticas letradas de la clase de LM. 


\begin{abstract}
Estudiante 7: porque no están pagando una estructura ni nada de eso, ni costos de agua,
Profesora: ¿esa es una ventaja competitiva o comparativa? mejor dicho, a ese negocio le podemos hacer la competencia ya isí o no?, ya con lo que sabe ya le pone la competencia, entonces, ila ventaja que es competitiva o comparativa? Efecto motivador: esa era mi intención y el ejercicio era que se despertaran.

Entonces, sigamos todavía tenemos tiempo. [Organiza grupos de trabajo] tienen quince minutos para organizar la presentación de segmentación, en quince minutos todos tienen que pasar y decir algo sobre ese punto y ustedes de posicionamiento, saquen sus lecturas, los resúmenes

Estudiantes: [Grupo l se presenta]

Profesora: Ya, entonces, miren, cuando nosotros estamos hablando de segmentación y posicionamiento generalmente estamos haciendo el mismo ejercicio, mentalmente se hacen 0 se utilizan las mismas definiciones en el mismo momento, y ese momento en el plan de mercadeo, que hace parte del plan de negocios, es lo primerito que uno hace con toda la información que tiene, es decir, lo primero que tengo que hacer es definir cuál es el mercado, al cual me voy a dirigir y cómo me voy a dirigir a ese mercado para que me recuerde y me compre a mí y no a usted ilisto? Esa es la clave de este ejercicio, entonces, es pertinente que yo les presente, antes de que ustedes hagan su presentación, la definición de Lamb y Hair de lo que es un mercado. Miren, mercado es un grupo de personas, las caritas felices o empresas en el caso suyo, los frigoríficos, según lo que hemos hablado en esta clase, que tiene una necesidad o sea tiene que sentir esa necesidad, esa carencia o esas ganas de tener lo que el vecino tiene, tiene que tener capacidad de compra y esto es pecaminoso principalmente para los que están pensando en fundaciones; su mercado objetivo es quien pueda comprar —tiene que tener capacidad de compra - sino, no se define como mercado en el contexto del mercado capitalista. Debe tener la voluntad y la posibilidad de comprar; estas características las voy a analizar mejor la próxima clase, pero son bacanas para que podamos, entonces, así hablar de los dos temas rápidamente: segmentación, escucho a los ingenieros, vayan pasando grupo de segmentación, escucho.
\end{abstract}

con los problemas del plan de mercadeo, el análisis del problema por parte de los participantes, la conexión con lo leído, el conjunto de recomendaciones de la profesora, la retroalimentación de ella como experta, la modificación o la afirmación del pensamiento y la actuación del estudiante en la resolución de problemas. Todo en un proceso dialógico. En la Figura 2 se presenta un esquema que resume este marco de interacción en torno al género plan de mercadeo.

Las prácticas de literacidad disciplinar tienen en el anterior marco un papel definitivo, dado que guían las formas de ser, hacer y pensar del ingeniero. Así mismo, se asocian con la resolución de problemas en conexión con el plan de mercadeo que desarrollan para el producto ideado por los estudiantes en un escenario industrial/organizacional hipotético, que se rige por los principios de productividad y optimización en línea con lo que se espera de su formación como ingenieros industriales.

\section{Análisis de las entrevistas a estudiantes}

A continuación, se presentan los principales hallazgos de las entrevistas realizadas, en las tres categorías identificadas, a saber, el proceso de escritura, el género plan de mercadeo y la construcción de la identidad disciplinar.

\section{Extractos sobre "cuestiones relativas al proceso de escritura}

1a [Escribir] fue un poco difícil, ya que éramos seis personas en el grupo de trabajo y todas redactamos diferente, lo cual hace que en el trabajo se diferencia la parte que realizó cada estudiante y no se vea una uniformidad en la redacción de este. Entonces, al final siempre intentaba revisar todo el trabajo y ver que fue coherente tanto la forma del trabajo (redacción) como el fondo (conceptos, ideas, ejecución, etc.). Esto se debe a que coordinar para reunirnos seis personas era muy difícil, entonces, siempre lo hacíamos por Google Drive y nos dividíamos las partes del trabajo; además era un proyecto extenso, por lo cual, si nos poníamos los seis a hacer el mismo punto juntos, no hubiera sido posible terminar a tiempo.

1b Con respecto al proceso de planeación [de la escritura] creo que es de suma importancia, ya que todos los integrantes del grupo planeábamos antes de escribir el texto cada punto y lo que íbamos a poner en este, para que todo fuera coherente a lo largo del plan de mercadeo. Y, por otro lado, el proceso de revisión también fue muy importante, ya que como fueron tres entregas, generalmente en la siguiente entrega debíamos corregir lo que tuvimos mal en la anterior, entonces, siempre debíamos revisar cada error y corregirlo. 


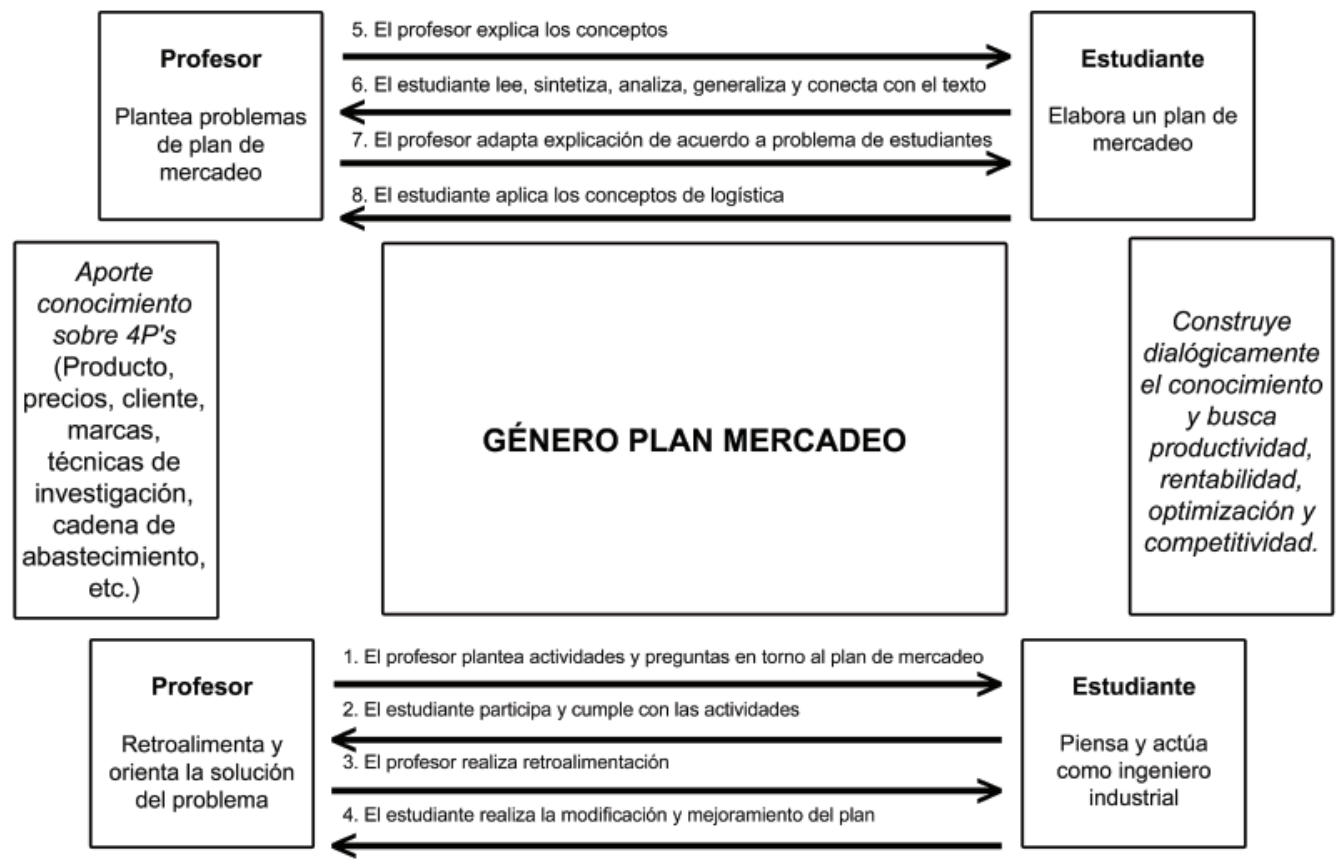

Figura 2 Marco de interacción en torno al plan de mercadeo.

1c. En mi grupo siempre tuvimos una buena citación, puntuación, manejo de voz y registro, por lo cual no hubo retroalimentación en estos factores. Por otro lado, con respecto a coherencia en la segunda entrega sí tuvimos errores en las conclusiones, porque no eran coherentes; por ejemplo: Nosotros afirmamos en las conclusiones que "toda la población era [...], toda la población tenía [...], etc.”, o sea nos referimos a toda la población cuando en realidad sólo podíamos concluir sobre la pequeña muestra que hicimos, y a partir de esta no es posible hacer afirmaciones sobre toda la población.

De acuerdo a lo planteado en los ejemplos 1a a 1c, entre las cuestiones relativas a la escritura se nombraron especialmente problemas, dificultades o aspectos por tener en cuenta, como coherencia, cohesión, normas de citación, ortografía, puntuación, redacción, fases de la escritura, voz y registro como autores, más las dificultades de escribir en grupo y cómo la herramienta Google Drive ${ }^{\circledR}$ les facilitó trabajar. Con ello, se muestra la importancia que le otorgan a la escritura basada especialmente en cuestiones gramaticales, incluso, también se evidencia la preocupación por la citación. Las respuestas de los estudiantes revelan que su concepción de escritura se asocia también a "las deficiencias en la gramática y la ortografía”, lo cual se relaciona con el modelo de escritura basado en las "habilidades", que intenta "arreglar" los problemas solo desde características superficiales de la forma lingüística (Lea y Street, 1998).

\section{Extractos sobre el género plan de mercadeo}

2a Al escribir el plan de mercadeo se tuvieron algunos problemas al comienzo, ya que no hacemos trabajos tan estructurados y con exigencias precisas con tanta frecuencia, pero fue una buena enseñanza para futuros trabajos de otras materias. Se aprendieron conceptos nuevos de marketing y publicidad, canales de distribución y ventas al detalle.

2b El plan de mercadeo es un trabajo que no se debe realizar sólo teóricamente, puesto que se debe imaginar las implementaciones que se tendrán para atender a las necesidades de la gente, como se atacará a la competencia, cuál será su propuesta de valor y factor diferencia- 
dor, cómo llegará a ese mercado meta donde se encuentra el cliente potencial, etc. Y pienso que esto demuestra que hay decisiones que no se deben tomar desde dentro de la empresa, refiriéndome a si se cambiará un proceso, si se cambiarán unas materias primas, etc., sino que también se deben tomar decisiones en el entorno externo de la compañía y esto ayuda a que cuando se presenten problemas en la vida laboral de un ingeniero industrial, ya que no sólo se recurrirá a esos conocimientos de solucionar problemas internos, sino que se tendrá una visión de pájaro para ver soluciones globales que tengan aún un mayor impacto.

2c Mi experiencia realizando el plan de mercadeo ha sido buena, porque es una herramienta muy útil para desarrollar estrategias y vender un producto o servicio a un mercado objetivo. En un principio se requiere recolectar información de manera profunda acerca del mercado objetivo, ya que esta es la base para desarrollar este plan. Esta investigación se debe realizar por medio de fuentes confiables, como lo son: revistas científicas, tecnológicas y bases de datos. También consta de realizar investigación exploratoria (observar y hablar con las personas del mercado objetivo) para conocer los intereses de las personas y poder darle un enfoque más claro a la investigación.

2d Entender cómo funciona la logística de mercados actualmente a nivel global es básico y necesario en el proceso de formación en ingeniería industrial. Para un futuro laboral, el hecho de saber hacer un presupuesto para una entrevista, definir un formato de una entrevista, tener claros los conceptos y saber distinguir cuando hacer una entrevista y cuando una encuesta, poder hacer un plan de mercadeo, entender que son y para qué son las $4 p$ (plaza, producto, precio y promoción) y cómo usarlas, definir tiempos, costos, recursos, saber qué es el marketing y cómo implementarlo, entender qué factores influyen en las decisiones de compra del consumidor y entender el comportamiento del consumidor, saber cómo es la distribución de un producto y la cadena de abastecimiento son unos de los cuantos aprendizajes que me llevo de este curso y que considero son muy valiosos en $\mathrm{mi}$ aprendizaje y mi proceso de formación como futuro ingeniero industrial. 2e Al definir las estrategias de cada $p$, para los servicios de masajes, sauna y discoteca fue desafiante, ya que se debían tener en cuenta muchos aspectos, como lo son: las personas involucradas, los precios de cada servicio, las fases de cada proceso, la evidencia física y la forma como se medirían estas estrategias.

$2 f$ Escribir el plan de mercadeo ha contribuido a que yo desarrolle habilidades para redactar documentos, analizar datos, manejar programas de análisis estadísticos, y así, tomar buenas decisiones. Además, usar buenas fuentes bibliográficas y referenciar de forma correcta la información que se extrae de otros autores. Finalmente, fomenta el trabajo en equipo.

Los extractos $2 \mathrm{a}$ a $2 \mathrm{f}$ revelan que los estudiantes asumen un discurso profesional en torno a lo que escriben; los géneros constituyen "prácticas discursivas dominantes, que se encuentran estandarizadas y reguladas institucionalmente, y por tanto cumplen un rol clave en los campos de desempeño escolar y laboral respectivos" (Navarro, 2010, p. 1297). El discurso de los estudiantes muestra que a través del diseño de un producto para un cliente real o potencial aprenden temas disciplinares, actitudes que asumen los ingenieros, adicionalmente, sobre oportunidades de marketing y toma de decisiones. Las prácticas comunicativas de los estudiantes, la audiencia (cliente real o potencial) y los objetivos de aprendizaje estaban ligados al contexto académico, el cual a su vez se vincula al contexto del trabajo, dado que los planes de mercadeo estaban conectados explícitamente con un cliente real o potencial.

Los ejemplos anteriores evidencian que los estudiantes al involucrarse en la planeación y la escritura del género afianzan los temas de la clase en cuanto a conceptualizaciones sobre marketing, ventas, formulación de indicadores, mercado objetivo y habilidades en la toma de decisiones y el trabajo en equipo. En ingeniería, el aprendizaje de los conceptos y las temáticas se dan en torno a objetos, procesos, productos de la realidad. Como advierte Winsor (1990), la ingeniería es 
el conocimiento sobre objetos y cómo construirlos, más allá del edificio real en sí es necesariamente un campo vinculado a los símbolos. Es decir, incluso este campo que parece tan atado a la realidad física se logra inevitablemente a través del lenguaje. (p. 59, traducción propia)

De esta manera, en las prácticas de enseñanza se hace un paralelo entre lo que sucede en la realidad y el modo en que debe actuar, pensar y hacer el ingeniero. La lectura y la escritura constituyen un insumo que generalmente es aprovechado como punto de partida para conectar con actividades y discursos del campo disciplinar. De lo expresado por los entrevistados, se evidencia que el modo de actuar, pensar y hacer del ingeniero industrial en conexión con la escritura del plan de mercadeo se asocia entre otros a:

- Entender los factores que influyen en las decisiones de compra y el comportamiento del consumidor (Véase 2 b y $2 c$ ).

- Diseñar investigaciones para comprender el comportamiento del consumidor (Véase $2 \mathrm{~b}$ y 2c).

- Calcular tiempos, costos, materiales, recursos en un proceso de producción (Véase $2 \mathrm{~d}$ ).

- Definir las estrategias para cada P (plaza, producto, precio y promoción) (Véase $2 \mathrm{~d}$ y $2 \mathrm{e}$ ).

- Diseñar un plan de mercadeo y tomar decisiones a partir del conocimiento de los consumidores (Véase $2 \mathrm{~d}$ ).

- Diseñar y optimizar rutas, canales de distribución y frecuencias en el transporte (Véase 2a y $2 d)$.

- Entender el proceso de distribución del producto y la cadena de abastecimiento (Véase 2a y 2d).

- Escribir el plan de mercadeo articulado a tomar decisiones en tiempos establecidos (Véase 2f).

\section{Extractos sobre identidad disciplinar}

3a Sí, lo veo como un trabajo esencial [la elaboración del plan de mercadeo] que debe aprender un ingeniero industrial, ya que se estudian maneras de cómo mejorar las utilidades en el momento de las ventas y cómo saber desde el marketing, cómo utilizar herramientas de ingeniera como: Regresión o Anovas y estrategias para fijar precios, cómo ayudan a fijar un mercado y encontrar una necesidad para lograr nuestros objetivos de venta de un producto o servicio.

3b He aprendido conceptos y prácticas de marketing, me ha reforzado conocimientos de muestreo y estadística, logré ver variables determinantes al momento de posicionar un producto en el mercado, entendí la importancia que tiene el mercadeo en nuestra carrera y que es importante como ingeniero no dejar al azar estos estudios para que en un futuro logremos desempeñar nuestra profesión con éxito.

$3 c$ Contribuye a mi formación como ingeniera industrial, ya que a partir de este aprendí que las decisiones para lanzar un producto o servicio nuevo, o realizar cambios en este a partir de las oportunidades de mejoras, no deben ser tomadas a la ligera o por opinión de la persona al mando, sino que se deben tomar decisiones basándose en el uso de otras herramientas adquiridas anteriormente como inferencia estadística.

3d La función principal de un ingeniero industrial es analizar datos para tomar decisiones basadas en técnicas estadísticas y matemáticas. En la asignatura logística de mercados, aprendimos técnicas nuevas para el análisis de datos, como lo es, el análisis factorial y discriminante. Además, aprendimos a usar programas para el análisis estadístico, como lo es SPSS.

3e Nosotros como ingenieros tenemos que solucionar problemas, que, si no se vende, no se generan utilidades, ninguna de las materias que se han visto o se deben ver sirven; que hay que reducir errores, calcular el tiempo y los costos; que la competencia actual es feroz y de esa poco se habla en otras asignaturas; que se debe cultivar ese espíritu de competencia para poder enfrentar los retos que se nos van a presentar como ingenieros industriales.

3f La verdad sí, ya que no es un trabajo netamente teórico o de investigación, el plan de mercadeo tienen múltiples categorías como 
lo es la parte exploratoria, de investigación, cuantitativa, cualitativa, de ideas, de propuestas, estrategias, costos, objetivos, indicadores y de más que son habilidades que un ingeniero industrial durante la carrera en las diferentes materias que cursa de algún u otro modo tendrá que aplicar y usar, es por esto que trabajos de este estilo ayudan a reunir en un solo proyecto la mayoría de habilidades, esto hace que uno aterrice y se dé cuenta en realidad la labor que tendrá que hacer cuando salga pues la idea de un ingeniero industrial es precisamente esa, ser capaz de responder y desarrollarse en diferentes áreas pues el conocimiento básico ya lo tiene.

3g. En el futuro me veo con mi propia empresa, desarrollando productos, como emprendedor y no como empresario, pero no puedo salir a la calle y simplemente decir voy a lanzar una nueva línea de productos alimenticios sin previamente haber hecho una investigación exhaustiva con relación a los temas vistos en la clase de logística de mercados. Estudiar cómo se comporta el consumidor, qué estrategias se van a implementar para atraer al consumidor, qué estrategias usaré para relacionarme con los proveedores, cuál será el atributo diferenciador de mi producto, cómo aplico la matriz DAFO para entender el contexto de la empresa, qué análisis estadísticos responden a mis problemas y muchas otras cosas que sólo se aprenden en esta clase y mediante la lectura de todos estos temas.

Las respuestas anteriores evidencian que la lengua escrita constituye una herramienta fundamental para construir conocimiento, en la medida en que posibilita la interacción del estudiante con los textos que lee. Se trata de un proceso de adquisición de la comprensión de un género, que apoya el proceso de enculturación del estudiante, esto es, su producción escrita se articula a objetivos específicos y participa en actividades discursivas en las que circula el conocimiento dentro de una comunidad disciplinaria (Carlino, 2013). De lo expresado por los entrevistados se evidencia que la identidad disciplinar del ingeniero industrial en conexión con la escritura del plan de mercadeo se asocia también a:

- Reducir errores (Véase 3d).
- Definir objetivos, indicadores o estrategias de marketing con respecto a un producto o un mercado (Véase 3a).

- Lograr altas ventas (Véase 3a y 3d).

- Leer y usar normas y estándares para planear, hacer, ejecutar y controlar procesos o productos (Véase 3g).

- Plantear modelos matemáticos para solucionar problemas (Véase 3b, 3c, 3d y 3g).

- Analizar datos cuantitativos especialmente (Véase 3b, 3c, 3d y 3f).

Como se ha argumentado, la identidad disciplinar hace referencia a las prácticas y a los discursos que llevan a los estudiantes a ser, hacer y pensar como ingenieros. El conocimiento de la clase de LM se produce, entre otros, mediante la escritura del plan de mercadeo, el cual era documentado teórica y metodológicamente, y retroalimentado a lo largo del semestre. La construcción del plan era enriquecida por entrevistas, análisis de datos recopilados por los estudiantes, que luego eran descritos a través de explicaciones, pruebas, hipótesis, diagramas, gráficos, en definitiva, códigos establecidos por los ingenieros. La escritura de este género se constituyó en un trabajo que ponía a los estudiantes a pensar como ingenieros. De acuerdo con Lamb et al. (2011), un plan de mercadeo es: "el proceso de crear y mantener un buen acoplamiento entre los objetivos y recursos de una compañía y las oportunidades en evolución del mercado. La meta de la planeación estratégica es alcanzar la rentabilidad y crecimiento a largo plazo" (p.24). En el programa del curso se define la estructura del plan de mercadeo, como aparece en la Tabla 5.

Para llegar a esta versión que da alcance a los puntos de la Tabla 5, los grupos debían haber identificado el mercado objetivo, los consumidores, hacer entrevistas y encuestas y categorizarlas a través de verbatims, citando segmentos concretos de la entrevista y atribuyéndoles un código. A partir de este trabajo de campo inicial exploratorio, los estudiantes preparaban la primera parte de su plan de mercadeo, que consta de lo siguiente, como se explica en la Tabla 6 . 
Tabla 5 Estructura de un plan de mercadeo

\begin{tabular}{l} 
Hoja de presentación \\
Resumen ejecutivo \\
Contexto global y local \\
Describir el sector industrial a nivel internacional y nacional. \\
Utilizar como fuentes de información secundaria. \\
Definición del mercado objetivo \\
Utilizar como fuentes de información secundaria, observación di- \\
recta y resultados de la investigación de mercados. \\
Justificar de acuerdo a criterios de segmentación utilizados \\
Definición de la estrategia de posicionamiento \\
Justificar la estrategia de acuerdo a la información relacionada \\
con la competencia del producto o servicio propuesto. \\
Presentar análisis de la competencia. \\
Atributo Diferenciador de su propuesta. \\
Objetivo general del plan de mercadeo \\
Indicador con el que va a medir el objetivo General del Plan de \\
Mercadeo \\
Objetivos Específicos para cada variable controlable del Plan de \\
Mercadeo \\
Indicadores con los que va a medir cada objetivo específico del \\
Plan de Mercadeo \\
Estrategia para cada Objetivo de cada P. \\
Describa las actividades, responsables, tiempo y costo para cada \\
Referencias \\
Bibliografía \\
\hline
\end{tabular}

Fuente: Elaborada con base en el programa del curso.

En la segunda entrega del plan se esperaba que los estudiantes "diseñaran y realizaran una encuesta, la tabularan en un archivo de Excel $^{\oplus}$, y analizaran los datos (Tabla 7).

Se considera que en LM se desarrolla la identidad disciplinar articulada a la función epistémica de la escritura, dado que se evidencia una forma de enseñar escritura más allá de consideraciones gramaticales o de reglas estáticas y formales. Se evidencia que el conocimiento retórico del género puede potenciar la naturaleza dinámica y social de la escritura, como lo plantea Winsor (1996): "Un principiante en cualquier área debe aprender a ver el mundo
Tabla 6 Primera entrega del plan de mercadeo

Descripción general del sector a nivel nacional e internacional
Descripción del mercado actual del producto o servicio en Bogotá
Comportamiento de compra, uso y disposición del bien/servicio
Actores del proceso de compra
Características del mercado
Perfil inicial del mercado objetivo
Aplicación de técnicas de investigación exploratoria
Diseño
Ejecución
Categorización
Presentar transcripción de la sesión de grupo y de la entrevista
a profundidad. Numerar los verbatims y relacionarlos con las
categorías
Análisis
Hipótesis
Presentar grabaciones de audio y video de la sesión de grupo y de
la entrevista a profundidad
Primer esquema propuesto de la estrategia que se planteará en
el plan de mercadeo, que permita establecer diferenciación en
su propuesta

Fuente: Programa del curso.

como lo hacen otros miembros del grupo" (p. 164). Esto se observa cuando el estudiante asume roles profesionales y se pregunta por ¿qué va en cada parte de la estructura del plan de mercadeo?; ¿qué objetivos comunicativos persiguen?; ¿qué técnicas usarán para recopilar y analizar datos?; ¡cómo presentar los datos comprensivamente?, etc. Aquí, la interacción entre los estudiantes y la profesora les ayuda a ser conscientes de las características retóricas del género estudiado.

A modo de recapitulación de las categorías estudiadas, se encontró que efectivamente las prácticas de literacidad disciplinar reflejan la conexión entre la lectura y la escritura, no a través de un simple documento técnico, sino mediante un informe que da cuenta del "proceso de inscripción" (inscribing process) (Latour y Woolgar, 1986[1979]). De esta forma, el estudiante se involucra en el proceso de producción del texto y se identifica en su profesión. Las inscripciones suponen transformaciones 
Tabla 7 Segunda entrega del plan de mercadeo

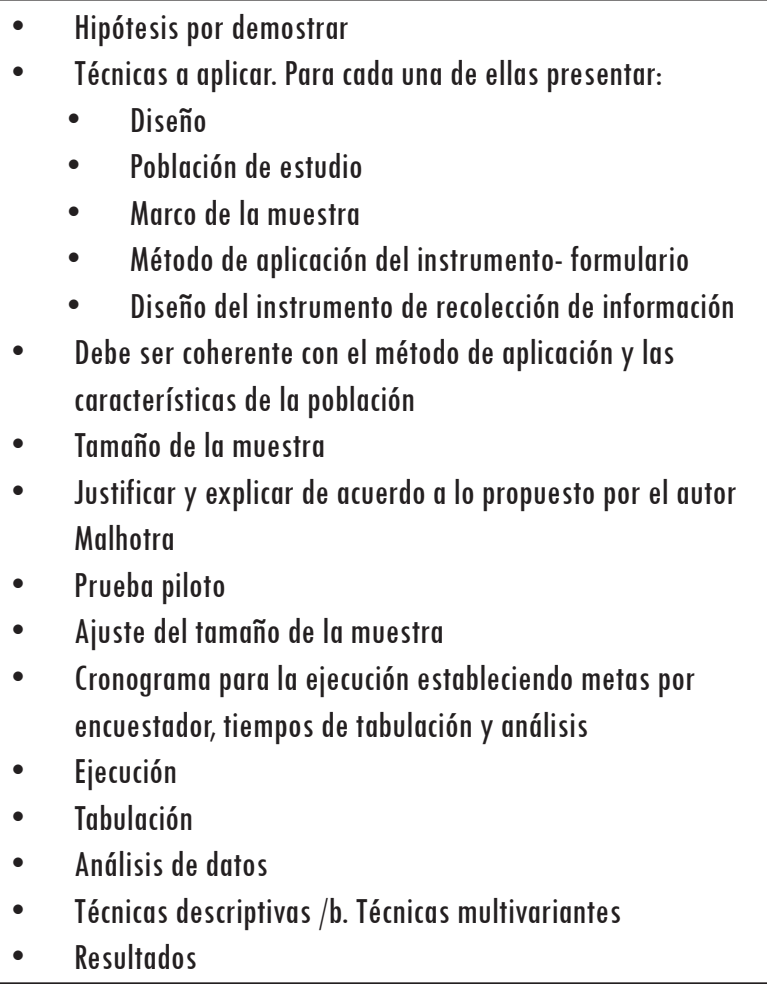

Fuente: Programa del curso.

simbólicas a través de lo que se escribe, pues el documento cambia a medida que incorpora la retroalimentación del profesor, los hallazgos del estudiante y la comunicación que como equipo generan quienes producen el plan de mercadeo, en este caso. A través de la escritura, los ingenieros analizan problemas de un mundo real capitalista (perfil del consumidor, mercados objetivo, factores diferenciadores, las P: producto, plaza, promoción, precio, estrategias para cada $\mathrm{P}$, actividades, tiempos, costos, etc.). En el plan deben integrar lo aprendido en las lecturas, así como realizar análisis matemáticos en Excel y en SPSS Statistics, y como se evidenció en los extractos de la entrevista a los estudiantes y en la estructura misma del plan de mercadeo (Tabla 5), entre las tareas implicadas está:

- Incorporar conceptos, justificaciones, síntesis, generalizaciones de las lecturas.
- Escribir a partir de una lectura rigurosa y generar relaciones de intertextualidad.

- Solucionar un problema y usar métodos adecuados para ello.

- Seleccionar una población objetivo.

- Identificar unos procedimientos basados en costos, tiempos y normas.

- Dominar una estructura de presentación del género (plan de mercadeo).

- Desarrollar estrategias de control de las variables (actividades, responsables, tiempo, costos de las $4 \mathrm{P})$.

- Seleccionar bibliografía para justificar los datos expresados.

- Desarrollar gráficos, tablas, histogramas, flujogramas que representen datos.

- Usar técnicas de estadística descriptiva.

- Realizar análisis de datos a través de diferentes técnicas metodológicas.

- Realizar pruebas de hipótesis.

- Usar matrices como DAFO para diagnosticar y determinar estrategias de intervención.

- Realizar análisis clúster. ${ }^{7}$

- Trabajar colaborativamente.

Los estudiantes ganan familiaridad y experiencia en la escritura del plan de mercadeo, y para ello, ponen en práctica las tareas anteriormente enunciadas, lo cual se constituye en un vehículo importante para su proceso de enculturación a través de prácticas de lectura y escritura, además del marketing como marco epistémico. En las Figuras 3 y 4, se presentan dos ejemplos tomados de los planes de mercadeo realizados por los estudiantes que evidencian la inclusión de histogramas y clúster.

7 El análisis clúster es una técnica multivariante cuya idea básica es clasificar objetos formando grupos/conglomerados (clúster) que sean lo más homogéneos posible dentro de sí mismos y heterogéneos entre sí (Módulo estadística, Universidad de Granada). 


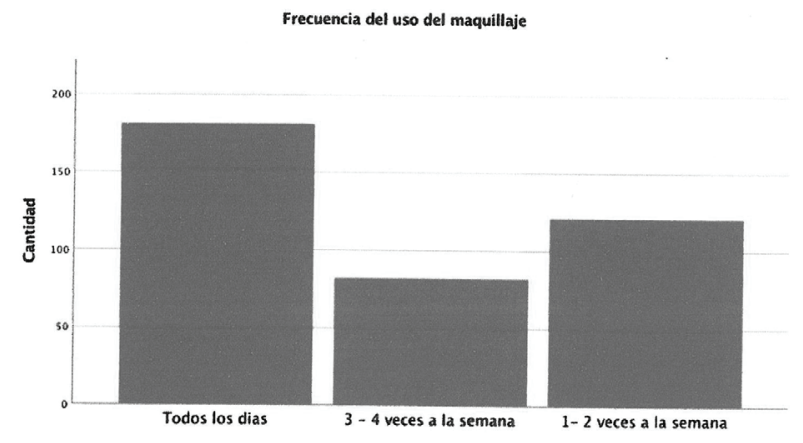

Figura 3 Representación de tablas e histogramas en un plan de mercadeo

Fuente: Trabajo de estudiante de la clase

Las Figuras 3 y 4 muestran solo algunas de las tareas de escritura implicadas en el desarrollo del plan de mercadeo, en el que se involucran sistemas de representación visual. Los ingenieros representan sus datos mediante gráficos, tablas, histogramas, flujogramas, que, a su vez, se complementan con explicaciones escritas. Igualmente de base existen unos datos cuantitativos para elaborar estos gráficos y ellos deben tomar decisiones para generar los datos y analizarlos. En definitiva, los estudiantes aprenden a desarrollar diferentes formas de comunicación para solucionar problemas en la empresa (reales o hipotéticos). Particularmente, el género plan de mercadeo les permite incorporar la escritura como un instrumento de aprendizaje y a la vez, entender las dinámicas de su profesión.

\section{Discusión}

A partir del análisis de los datos obtenidos de las observaciones de clases y de las entrevistas se encuentra que involucrar de modo decidido a los estudiantes en prácticas letradas en las que deban pensar críticamente y escribir, los lleva a profundizar en la comprensión de conceptos complejos y géneros especializados. De otro lado, los ingenieros en formación deben tener habilidades metacognitivas de síntesis, razonamiento, análisis de problemas, intervención y evaluación (Funke y Frensch, 2007). Por lo tanto, los estudiantes de ingeniería deberían ser capaces de tratar y resolver problemas complejos. Experiencias como la de LM revelan que vincular el aprendizaje de

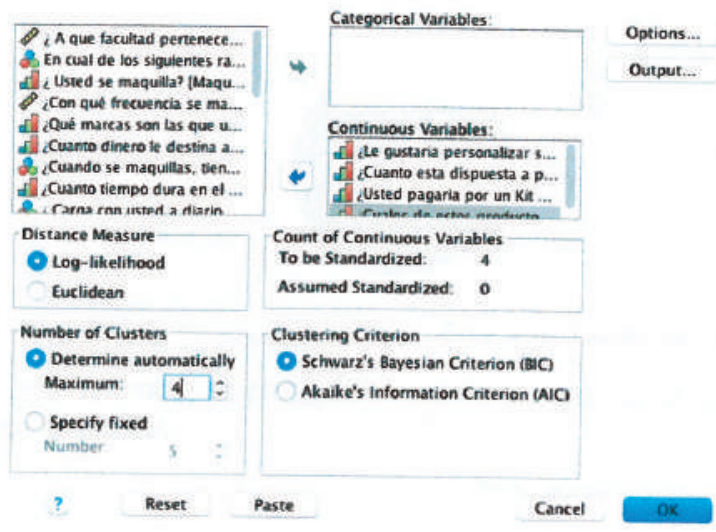

Figura 4 Representación de análisis clúster en un plan de mercadeo

Fuente: Trabajo de estudiante de la clase

géneros como el plan de mercadeo supone inscribirlos en actividades que simulan lo que sucedería en el ámbito profesional y cómo participar en su comunidad disciplinar (Artemeva, 2005; Winsor, 1996, 1999). La experiencia analizada evidencia cómo los estudiantes de ingeniería se vinculan paulatinamente a espacios disciplinares que junto con los expertos conectan géneros discursivos (orales y escritos), prácticas y discursos que les permiten socializar en sus comunidades y desarrollar su identidad profesional (Bazerman, 2002; Prior y Bilbro, 2012).

Se trata, entonces, de un aprendizaje basado en la experiencia que se apoya en la capacidad del estudiante para aplicar lo que lee en la organización de la información, en la contextualización de los datos, en la conexión de diferentes tipos de información y la aplicación de la misma a la solución de problemas de la vida real, articulando conocimientos sobre los modelos matemáticos, los conocimientos técnicos y de ingeniería, el uso de software especializado $\left(\right.$ Excel $^{\circ}$ y SPSS Statistics). Como se puede ver en el ejercicio del plan de mercadeo, el discurso utilizado por los estudiantes se relaciona con la identidad profesional de los ingenieros, quienes deben solucionar problemas y tomar decisiones, de ahí que sea fundamental la comprensión sobre modelos matemáticos, programas para analizar datos y todo lo que les permita configurar heurísticas específicas en la resolución de problemas de su dominio disciplinar. 
Como se señaló anteriormente las prácticas de literacidad en ingeniería se dan para aprender en torno a objetos, procesos, productos de la realidad. La lectura y la escritura como herramientas de mediación en la formación del estudiante apoyan la manera en que representa y reflexiona el ingeniero sobre realidades físicas (Winsor, 1990). En ese sentido, desde la clase observada se pudo evidenciar una preocupación por parte de la docente por apoyar los procesos implicados en la formación de la identidad disciplinar, porque el estudiante aprenda a ser, hacer y pensar como si estuviera en el trabajo, resuelva y tome decisiones como si estuviera en un contexto laboral real, que ponga en simetría su acción y su pensamiento, sus herramientas y un posible contexto.

El género analizado en este artículo permite a los estudiantes entender las dinámicas de investigación que involucran entrevistar y encuestar consumidores, analizar y tabular datos cualitativos y cuantitativos, definir un mercado objetivo, pensar estrategias de posicionamiento, definir objetivos asociados a indicadores, pensar estrategias de cada P (producto, plaza, promoción y precio), definir responsabilidades, tiempos, costos para cada $P$, establecer tablas de costos, hacer cálculos, etc. Es decir, involucrarse en una actividad propia de su disciplina, a través del conocimiento de un género, lo cual le permite desarrollar su identidad profesional y agenciar su experiencia, su pensamiento, su conocimiento, su acción como Ingeniero Industrial. De manera que la configuración que les plantea la profesora de escribir el plan de mercadeo a lo largo del semestre se constituye en una oportunidad de participar en prácticas auténticas de literacidad disciplinar que les permite a los estudiantes desarrollar su identidad profesional (Artemeva, 2009), poniendo en escena la función epistémica de la escritura.

\section{Conclusiones}

La clase de LM evidencia cómo pueden involucrarse los estudiantes en procesos de apropiación de escritura en géneros especializados, en las cuales el profesor como experto conoce las especificidades del discurso disciplinario, al tiempo que pone en juego la identidad disciplinar del ingeniero. Se trata de vincular a los estudiantes en prácticas específicas para determinar un mercado objetivo y vender un producto, lo cual implica recolectar datos, tener un marco conceptual, analizar la información y desarrollar un plan escrito que refleje esa identificación y dominio disciplinar referidos anteriormente. Se reconoce, además, que las tareas de escritura están altamente situadas (Prior, 1998), y las convenciones, las normas y las regulaciones discursivas varían disciplinarmente, dado que dependen de los contextos y los roles que desempeñan los estudiantes. También revela la necesidad de incorporar el contexto en la enseñanza de la escritura (Hyland, 2002), además de la comprensión de los géneros y las actividades que los rodean. Como se mostró en el análisis de la clase de LM, el ejercicio de los planes de mercadeo se realizó sobre iniciativas de los estudiantes cercanos a su contexto y sus necesidades; por esta razón se observa un predominio de mercados objetivo asociados al maquillaje, las bebidas energizantes, la ropa deportiva, dispositivos tecnológicos, etc.

De otro lado, en carreras como ingeniería industrial, la escritura académica se relaciona con el diseño de propuestas que involucran sistemas de representación externa (gráficos, esquemas, tablas, imágenes) para desarrollar información teórica, así mismo, como lo mostró el caso de LM se analizan datos cualitativos y cuantitativos. Igualmente, se espera que los estudiantes dominen normas, estándares y protocolos de escritura (p.e. las Tablas 5, 6 y 7), esto es, subyace una concepción de escritura que va más allá del modelo de "habilidades" (Lea y Street, 1998). Si bien en esta experiencia se evidencia la importancia que se le atribuye a escribir como "redactar bien" o "gramaticalmente bien", también se evidencia la articulación con tareas de investigación (muestreo, segmentación, tabulación de datos cualitativos), con la necesidad de tener claridad conceptual y de reconocer habilidades frente a la estructura retórica del género; incluso, con ver la escritura como un esfuerzo colectivo, que implica lectura 
comprensiva, discusión entre pares, relación con el contexto de los estudiantes (intereses personales y prácticas de trabajo orientadas a la industria), cronograma de tareas de escritura y revisión. De acuerdo con ello, las prácticas de escritura en contextos situados no son homogéneas ni uniformes $\mathrm{y}$ dependen de las interacciones y los fines que se persiguen de acuerdo a los temas y los dominios disciplinares, los cuales han de ser considerados en los procesos formativos de la parte comunicativa de los ingenieros.

Para finalizar, es probable que si se vincula la experiencia analizada a programas de escritura y a formas de revisión y evaluación específicas, de seguro se favorecerá la comprensión sobre temas relacionados con la escritura académica, la identidad y el dominio disciplinar. Se podría involucrar a los estudiantes y a los profesores en la comprensión retórica y discursiva de géneros especializados, a fin de desarrollar de modo más explícito estrategias de enseñanza y evaluación. Este trabajo supone la vinculación de expertos del área de lenguaje y de áreas disciplinares específicas, que favorezcan la reflexión y el diálogo sobre tipos de datos y problemas que abordan en áreas específicas, modos de acceder, interrogar, comunicar y evaluar el conocimiento disciplinar y formas de potenciar la función epistémica de la lectura y la escritura.

\section{Referencias}

Artemeva, N. (2005). A time to speak, a time to act. A rhetorical genre analysis of a novice engineer's calculated risk taking. Journal of Business and Technical Communication, 19(4), 389-421.

Artemeva, N. (2009). Stories of becoming: A study of novice engineers learning genres of their profession. En Ch. Bazerman, A. Bonini, y D. Figueiredo (Eds.), Genre in a changing world. Fort Collins, CO: WAC Clearinghouse and Parlor Press.

Baillie, C. y Johnson, A. (2008). A threshold model for attitudes in first year engineering students. En Threshold concepts within the disciplines (pp. 129-141). Rotterdam, The Netherlands: Sense publishers.

Bajtín, M. (1985). Estética de la creación verbal. Madrid: Siglo XXI.
Ballou, R. (1999). Business logistics management. México: Prentice Hall.

Barton, D. y Hamilton, M. (2000). Literacy practices. En D. Barton, M. Hamilton y R. Ivanic (Eds.), Situated literacies: Reading and writing in context (pp.7-14). Londres: Routledge.

Bazerman, Ch. (1985). Physicists reading physics: Schemaladen purposes and purpose-laden schema. Written Communication, 2, 3-23.

Bazerman, Ch. (2002). Genre and identity: Citizenship in the age of the internet and the age of global capitalism. En R. Coe, L. Lingard y T. Teslenko (Eds.), The rhetoric and ideology of genre (pp. 13-37). Cresskill, NJ: Hampton Press.

Bazerman, Ch. (2011). Genre as social action. En J. Gee y M. Handford (Eds.), The Routledge handbook of discourse analysis. Londres: Routledge, Taylor and Francis Group.

Bean, J. (2011). Engaging ideas: The professor's guide to integrating writing, critical thinking, and active learning in the classroom (2. ${ }^{\mathrm{a}}$ ed.). San Francisco, CA: JosseyBass.

Berkenkotter, C. y Huckin, T. (1995). Genre knowledge and disciplinary communication: Culture/cognition/power. Hillsdale, NJ: Lawrence Erlbaum.

Bunton, D. (1999). The use of higher level metatext in Ph. D. theses. English for Specific Purposes, 18, 41-56.

Camps, A., y Castelló, M. (2013). La escritura académica en la universidad. REDU. Revista de Docencia Universitaria, 11(1), 17-36. doi:https://doi.org/10.4995/ $\underline{\text { redu.2013.5590 }}$

Carlino, P.(2013). Alfabetización académica diez años después. Revista Mexicana de Investigación Educativa, 18(57), 355-381. Disponible en http://www. redalyc.org/articulo.oa?id=14025774003.

Cisneros, M. y Olave, G. (2012). Redacción y publicación de artículos cientificos: un enfoque discursivo. Bogotá: Editorial ECOE.

Creswell, J. (2013). Qualitative inquiry \& research design: Choosing among five approaches (3. ${ }^{\mathrm{a}} \mathrm{Ed}$.). Thousand Oaks, CA: SAGE.

De Tezanos, A. (2004). Una etnografía de la etnografía. Aproximaciones metodológicas para la enseñanza del enfoque cualitativo-interpretativo para la investigación social. Bogotá: Anthropos.

Fairclough, N. (1992). Discourse and social change. Cambridge: Polity Press.

Funke, J. y Frensch, P. (2007). Complex problem solving: The European perspective -10 years after. En D. 
H. Jonassen (Ed.), Learning to solve complex scientific problems (pp. 25-47). Nueva York: Erlbaum.

Gee, J. P. (1996). Social linguistics and literacies: Ideology in Discourses. Londres: Taylor \& Francis.

Haas, C. (1994). Learning to read biology: One student's rhetorical development in college. Written Communication, 11(1), 43-84. DOI: https://doi. org/10.1177/0741088394011001004

Hamilton, M. (2000). Expanding the new literacy studies: Using photographs to explore literacy as social practice. En D. Barton, M. Hamilton y R. Ivanic (Eds.), Situated literacies: Reading and writing in context (pp. 16-34). Londres: Routledge.

Hernández-Zamora, G. (2016). Literacidad académica. México: Universidad Autónoma Metropolitana.

Herrington, A. (1985). Writing in academic settings: A study of the contexts for writing in two college chemical engineering courses. Research in the Teaching of English, 19(4), 331-361.

Hyland, K. (2004 [2000]). Disciplinary discourses. Social interactions in academic writing. Michigan: The University of Michigan Press.

Hyland, K. (2002). Specificity revisited: How far should we go now? English for Specific Purposes, 21, 385-395.

Klein, I. (2007). El taller del escritor universitario. Buenos Aires: Prometeo.

Lamb, Ch., Hair, J. y McDaniel, C. (2011). Marketing (11. ${ }^{a}$ Ed.). México: Cengage Learning.

Latour, B. y Woolgar, S. (1986[1979]). Laboratory life: the construction of scientific facts. Princeton: Princeton University Press.

Lea, M. y Street, B. (1998). Student writing in higher education: an academic literacies approach. Studies in Higher Education, 11(3), 182-199.

Malhotra, N. K. (2008). Investigación de mercados: un enfoque aplicado (5. Ed.). México: Pearson Educación.

Marinkovich, J., Sologuren, E., y Shawky, M. (2018). The process of academic literacy in Civil Engineering Informatics: An approach to academic writing and its genres in a learning community. Círculo de Lingüistica Aplicada a la Comunicación, 74, 195220. DOI:10.5209/CLAC.60520

McCutchen, D., Teske, P.y Bankston, C. (2008). Writing and cognition: Implications of the cognitive architecture for learning to write and writing to learn. En C. Bazerman (Ed.), Handbook of research on writing: history, society, school, individual, text (pp. 554-578).
Nueva York y Londres, EE. UU. y Reino Unido: Taylor \& Francis.

Moje, E. (2010). "Desarrollo de discursos, literacidades e identidades disciplinares: ¿cuál es su relación con el conocimiento? En G. López-Bonilla y C. Pérez Fragoso (Coords.), Discursos e identidades en contextos de cambio educativo. México: Editorial Plaza y Valdés/ Benemérita Universidad Autónoma de Puebla.

Montes, M. y López-Bonilla, G. (2017). Literacidad y alfabetización disciplinar: enfoques teóricos y propuestas pedagógicas. Perfiles Educativos, 39(165), 162-178. Disponible en: http:// www.scielo.org. $\mathrm{mx} /$ scielo.php ? script $=$ sci arttext\&pid=S0185-26982017000100162\&lng=e $\underline{s \& t \operatorname{lng}=e s}$

Narváez-Cardona, E. (2016). Latin-American writing initiatives in Engineering from Spanish-speaking countries. Ilha do Desterro, 69(3), 223-248. https:// dx.doi.org/10.5007/2175-8026.2016v69n3p223

Natale, L. (Ed.) (2012). En carrera: escritura y lectura de textos académicos y profesionales. Los Polvorines: UNGs.

Navarro, F. (2010). ¿Qué son los géneros profesionales? Apuntes teórico-metodológicos para el estudio del discurso profesional. En Actas del IV Congreso Internacional de Letras "Transformaciones culturales. Debates de la teoría, la critica y la lingüistica en el bicentenario". Buenos Aires, Argentina.

Navarro, F. y Revel Chion, A. (2013). Escribirpara aprender. Disciplinas y escritura en la escuela secundaria. Buenos Aires: Paidós.

Navarro, F. y Aparicio G. (2018). Manual de lectura, escritura y oralidad académicas para ingresantes a la universidad. Buenos Aires: Universidad Nacional de Quilmes.

Nesi, H. y Gardner, S. (2012). Genres across the disciplines. Student writing in higher education. Cambridge, Reino Unido: Cambridge University Press.

Nogueira, S. (2003). Manual de lectura y escritura universitarias: prácticas de taller. Buenos Aires: Biblos.

Paltridge, B. (2002). Thesis and dissertation writing: An examination of published advice and actual practice. English for Specific Purposes, 21, 125-143.

Pires, S. y Carretero, L. (2007). Gestión de la cadena de suministro. Madrid: McGraw Hill.

Prior, P. (1998). Writing/disciplinarity. Mahwah, NJ: Lawrence Erlbaum Associates.

Prior, P.y Bilbro, R. (2012). Academic enculturation: Developing literate practices and disciplinary identities. En M. Castelló y Ch. Donahue (Eds.), University 
writing: Selves and texts in academic (pp.19-31). Bingley, uk: Emerald.

Quick, C. (2012). From the workplace to academia: Nontraditional students and the relevance of workplace experience in technical writing pedagogy. Technical Communication 2uarterly, 21(3), 230-250.

Rivera-Camino, J. (2009). Dirección de marketing. Fundamentosy aplicaciones (3. ${ }^{a} \mathrm{Ed}$.). España: Esic Editorial.

Schreier, M. (2012). Qualitative content analysis in practice. Thousand Oaks, ca: Sage.

Shaw, P. (2000). Towards classifying the arguments in research genres. En A. Trosberg (Ed.), Analysing professional genres (pp. 41-56). Amsterdam: John Benjamins.

Stagnaro, D., y Natale, L. (2015). Géneros y formación ingenieril: de la universidad a la industria. Magis, Revista Internacional de Investigación en Educación, 8(16), 91108. https://doi.org/10.11144/Javeriana.m8-16.gfiu

Street, B. (2005). At last: Recent applications of new literacy studies in educational contexts. Research in the Teaching of English, 39(4), 417-423.

Swales, J. (1990). Genre analysis: English in academic and research settings. Cambridge: Cambridge University Press.

Swales, J. (2004). Research genres: Explorations and applications. Cambridge: Cambridge University Press.

Swales, J. y Lindemann, S. (2002). Teaching the literature review to international graduate students. En A. Johns
(Ed.), Genres and the classroom -Multiple perspectives (pp. 105-119). Mahwah, NJ: Lawrence Erlbaum.

Universidad de Granada (s. f.). Módulo estadística. Disponible en http://wpd.ugr.es/ bioestad/guia-spss/ practica-8/

Wells, G. (1990). Talk about text: Where literacy is learned and taught. Curriculum Inquiry, 20(4), 369-405.

Wineburg, S. (1991). Historical problem solving: A study of the cognitive process used in the evaluation of documentary and pictorial evidence. Journal of Educational Psychology, 83(1), 73-87.

Winsor, D. (1990). Engineering writing/writing engineering. College Composition and Communication, 41(1), 58-70.

Winsor, D. (1996). Writing well as a form of social knowledge. En A. H. Duin y J. Hansen (Eds.), Nonacademic writing: social theory and technology (pp. 157-172). Mahwah, NJ: Lawrence Erlbaum Associates.

Winsor, D. A. (1999). Genre and activity systems. The role of documentation in maintaining and changing engineering activity systems. Written Communication, 16(2) 200-224. https://doi. org/10.1177/0741088399016002003

Winsor, D. A. (2003). Writingpower: Communication in an engineering center. Nueva York: State University of New York Press.

How to reference this article: Moreno-Mosquera, E. (2019). La escritura de géneros especializados y su relación con la identidad disciplinar. Estudio de caso en ingeniería industrial. Íkala, Revista de Lenguaje y Cultura, 24(2), 249-269. DOI: 10.17533/udea.ikala.v24n02a04 